\title{
A novel downscaling technique for the linkage of global and regional air quality modeling
}

\author{
Y. F. Lam and J. S. Fu \\ Department of Civil and Environmental Engineering, University of Tennessee, Knoxville, TN, USA
}

Received: 20 April 2009 - Published in Atmos. Chem. Phys. Discuss.: 28 July 2009

Revised: 21 November 2009 - Accepted: 26 November 2009 - Published: 7 December 2009

\begin{abstract}
Recently, downscaling global atmospheric model outputs (GCTM) for the USEPA Community Multiscale Air Quality (CMAQ) Initial (IC) and Boundary Conditions (BC) have become practical because of the rapid growth of computational technologies that allow global simulations to be completed within a reasonable time. The traditional method of generating IC/BC by profile data has lost its advocates due to the weakness of the limited horizontal and vertical variations found on the gridded boundary layers. Theoretically, high quality GCTM IC/BC should yield a better result in CMAQ. Unfortunately, several researchers have found that the outputs from GCTM IC/BC are not necessarily better than profile IC/BC due to the excessive transport of $\mathrm{O}_{3}$ aloft in GCTM IC/BC. In this paper, we intend to investigate the effects of using profile IC/BC and global atmospheric model data. In addition, we are suggesting a novel approach to resolve the existing issue in downscaling.

In the study, we utilized the GEOS-Chem model outputs to generate time-varied and layer-varied IC/BC for year 2002 with the implementation of tropopause determining algorithm in the downscaling process (i.e., based on chemical $\left(\mathrm{O}_{3}\right)$ tropopause definition). The comparison between the implemented tropopause approach and the profile IC/BC approach is performed to demonstrate improvement of considering tropopause. It is observed that without using tropopause information in the downscaling process, unrealistic $\mathrm{O}_{3}$ concentrations are created at the upper layers of IC/BC. This phenomenon has caused over-prediction of surface $\mathrm{O}_{3}$ in CMAQ. In addition, the amount of over-prediction is greatly affected by temperature and latitudinal location of the study domain. With the implementation of the algorithm, we have successfully resolved the incompatibility issues in the vertical layer structure between global and re-
\end{abstract}

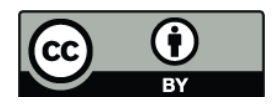

Correspondence to: J. S. Fu

(jsfu@utk.edu) gional chemistry models to yield better surface $\mathrm{O}_{3}$ predictions than profile IC/BC for both summer and winter conditions. At the same time, it improved the vertical $\mathrm{O}_{3}$ distribution of CMAQ outputs. It is strongly recommended that the tropopause information should be incorporated into any two-way coupled global and regional models, where the tropospheric regional model is used, to solve the vertical incompatibility that exists between global and regional models.

\section{Introduction}

Regional air quality models are designed to simulate the transport, production, and destruction of atmospheric chemicals at the tropospheric level. Particular interest is given at the planetary boundary layer (PBL) where human activities reside (Byun and Schere, 2006). Performance of the regional models depends greatly on the temporal and spatial quality of the inputs (i.e., emission inventories, meteorological model outputs, and boundary conditions). Recently, establishing proper boundary conditions (BCs) has become a crucial process as the effects of intercontinental transport of air pollutants (Heald et al., 2003; Lin et al., 2008; Chin et al., 2007) and enhancement of background pollutant concentrations emerged (Vingarzan, 2004; Ordonez et al., 2007; Fiore et al., 2003). Various studies suggested that utilizing dynamic global chemical transport model (CTM) outputs as the $\mathrm{BCs}$ for the regional air quality model would be the best option for capturing the temporal variation and spatial distributions of the tracer species (Fu et al., 2008; Byun et al., 2004; Morris et al., 2006; Tang et al., 2007). For example, Song et al., (2008) applied the interpolated values from a global chemical model, RAQMS, as the lateral BCs for the regional air quality model, CMAQ and evaluated simulated CMAQ results with ozone soundings. Simulations were performed on the standard CMAQ seasonal varied profile BCs and dynamic BCs from RAQMS. The results demonstrated

Published by Copernicus Publications on behalf of the European Geosciences Union. 
that the scenario with dynamic BCs performed better than the scenario with profile $\mathrm{BCs}$ in terms of the prediction of vertical ozone profile.

The quality of BCs depends on the vertical, horizontal, and temporal resolutions of global CTM outputs. The latitudinal location and seasonal variation are also playing an important role, which defines the tropopause height that influences the vertical interpolation process between global and regional models. (Bethan et al., 1996;Stohl et al., 2003) In the MICS-Asia project, high concentrations of ozone (i.e., 500 ppbv) have been observed in CMAQ BCs when the regional model's layers reach above or beyond the tropopause height during the vertical interpolation process. (Fu et al., 2008) This high ozone aloft in BCs has created problems for the regional tropospheric model (such as CMAQ) since it does not have a stratospheric component or stratospheretroposphere exchange mechanism. As a result, unrealistically high ozone concentrations were observed at the surface layer during the regional CTM simulations. Tang et al. (2009) studied various CTM lateral BCs from MOZARTNCAR, MOZART-GFDL, and RAQMS. They observed that CTM BCs have induced a high concentration of ozone in the upper troposphere in CMAQ; this high ozone aloft quickly mixed down to the surface resulting in an overestimation of surface ozone. Mathur et Al., suggested that the overestimation of $\mathrm{O}_{3}$ might also be partially contributed by the inadequate representation of free tropospheric mixing due to the selection of a coarse vertical resolution (Mathur et al., 2008; Tang et al., 2009) Since the rate of vertical transport of flux is highly sensitive to temperature and moistureinduced buoyancies, correctly representing deep convection or flux entrainment at the unstable layer in the meteorological model becomes critical to modeling ozone vertical mixing. It should be noted that the single PBL scheme in the meteorological model is not sufficient to simulate the correct vertical layer structure on the broad aspect of environmental conditions (i.e., terrain elevation and PBL height) in the existing domain. As a result, it introduces uncertainties and errors to the process of determining vertical transport of $\mathrm{O}_{3}$ in the air quality model (Zangl et al., 2008; Perez et al., 2006) For the downscaling problem, Tang et al. (2009) has commented that using outputs of the global CTM (GCTM) as BCs may not necessarily be better than the standard profile-BC, which highly depends on location and time. The quick downward mixing in CMAQ has caused an erroneous prediction of surface ozone when both tropospheric and stratospheric ozone are included in the CTM BCs. (Al-Saadi et al., 2007; Tang et al., 2007; Tang et al., 2009) Therefore, correctly defining tropopause height for separating troposphere and stratosphere becomes crucial to the prevention of stratospheric influence during the vertical interpolation process for CMAQ and other regional CTMs simulation.

The tropopause is defined as the boundary/transitional layer between the troposphere and the stratosphere, which separates by distinct physical regimes in the atmosphere. The height of tropopause ranges from $6 \mathrm{~km}$ to $18 \mathrm{~km}$ depending on seasons and locations (Stohl et al., 2003). In the USA, the typical tropopause height in summer ranges from $12 \mathrm{~km}$ to $16 \mathrm{~km}$, but drops to $8 \mathrm{~km}$ to $12 \mathrm{~km}$ in winter (Newchurch et al., 2003). Various techniques were developed for identifying the altitude of tropopause, which are based on temperature gradient, potential vorticity (PV), and ozone gradient. In meteorological studies, such as satellite and sonde data analysis, temperature gradient method, also referred to as the thermal tropopause method, is the most commonly used technique, which searches the lowest altitude where the temperature lapse rate decreased to less than $2^{\circ} \mathrm{K} / \mathrm{km}$ for the next $2 \mathrm{~km}$ and defines that as tropopause. (WMO, 1986) In climate modeling, PV technique, referred to as dynamic technique, is often applied to define tropopause. PV is a vertical momentum up drift parameter and is expressed by PV unit (PVU). The threshold value of the tropopause lies between \pm 1.6 to $3.5 \mathrm{PVU}$ depending on the location on the globe (Hoinka, 1997), Recently, in an attempt to improve the regional model (i.e., the pure tropospheric model), CMAQ (to simulate ozone at the lower stratosphere) was performed using Potential Vorticity relationship. Location-independent correlation between PVU with ozone concentrations was applied to correct the near/above-tropopause ozone concentrations in CMAQ. The fundamental disadvantage of using such technique is the implementation of a single correlation profile (i.e., $R^{2}=0.7$ ) to represent the entire study domain (i.e., the Continental USA). It shows that a slight shift of PV value in the profile could result in a big change of ozone concentration, up to $100 \mathrm{ppbv}$. In addition, this profile may not be applicable for all locations in the domain due to the limited amount of data in the literature (Mathur et al., 2008). In GCTM downscaling, the ozone gradient technique, referred to as chemical tropopause or ozone tropopause, is more appropriate for defining tropopause since we have observed the stratospheric level of ozone (i.e., about $300 \mathrm{ppbv}$ ) at the level of thermal and dynamic tropopause (Lam et al., 2008).

Ozone tropopause is defined by atmospheric ozone concentration, which observes a sharp transition from low concentrations to high concentrations from troposphere to stratosphere. The defined $\mathrm{O}_{3}$ tropopause is consistently lower than the thermal and dynamic tropopause. (Bethan et al., 1996) The height of tropopause affects both the stratospheretroposphere exchange (STE) as well as the transport of $\mathrm{O}_{3}$ at upper troposphere. (Holton et al., 1995; Stohl et al., 2003) In global CTM, well-defined vertical profiles of troposphere, tropopause, and stratosphere are established for simulating STE, upper tropospheric advection, and other atmospheric processes. Collins (2003) estimated that the net $\mathrm{O}_{3}$ flux from the stratosphere could contribute 10 to $15 \mathrm{ppbv}$ of the overall tropospheric ozone. (Collins et al., 2003), where Stohl (2003) has found about $10 \%$ to $20 \%$ of tropospheric ozone are originated from stratosphere (Stohl et al., 2003). The advantage of employing CTM outputs as BCs gives a better representation of upper troposphere and the effect of STE can 
be taken into account. Although global CTM is capable of simulating tropospheric conditions, the temporal and spatial resolutions may not be sufficient to represent the daily and monthly variability of surface conditions since the monthly chemical profile of budget is used. Several researchers have demonstrated the outputs of global CTM can be used in the area of surface background conditions and trends (Park et al., 2006; Fiore et al., 2003). However, it also indicated that the global CTM is inadequate to predict the peak magnitude of $\mathrm{O}_{3}$ at the surface since it is not intended to describe detailed surface flux condition at a high temporal and spatial resolution. Therefore, the regional air quality model remains indispensable for simulating the surface $\mathrm{O}_{3}$ conditions.

In this study, we have developed a linking tool to provide lateral BCs of the USEPA Community Multiscale Air Quality (CMAQ) model with the outputs from GEOS-Chem (Byun and Schere, 2006; Lam et al., 2008; Li et al., 2005). One full year of GEOS-Chem data in 2002 are analyzed and summarized to explore the seasonal variations of $\mathrm{O}_{3}$ vertical profiles and tropopause heights in global CTM with available ozonesonde data in the USA are used to verify the performance of the GEOS-Chem model. Evaluations are conducted to measure the potential impact of changing tropopause height to the performance of the interpolated BCs toward the regional CTM. A new algorithm, "tropopausedetermining algorithm", which is based on chemical $\left(\mathrm{O}_{3}\right)$ tropopause definition, is proposed for the vertical interpolation process during downscaling to remove stratospheric effects from the global CTM toward the regional CTM. Verifications of the new algorithm are performed using three sets of CMAQ simulations, which are (1) the static lateral BCs from predefined profileis used as an experimental control for GEOS-Chem data inputs; (2) standard dynamic lateral BCs from GEOS-Chem using original vertical interpolation; and (3) the modified dynamic lateral BCs from GEOS-Chem, and is intended to show the improvement of the proposed idea using the observation data from ozonesonde and CASTNET. Moreover, it demonstrates the necessity of filtering the tropospheric portion of global GMC outputs for the inputs in regional air quality modeling.

\section{Description and configuration of models used}

In this study, GEOS-Chem global chemistry model output is used to provide lateral boundary conditions for the regional air quality model CMAQ, where meteorological inputs are driven by the MM5 mesoscale model. The model setups are described as follows.

\section{GEOS-Chem}

GEOS-Chem global chemistry model output is one of the most popular global models for generating BCs for the CMAQ regional model (Tesche et al., 2006; Morris et al.,

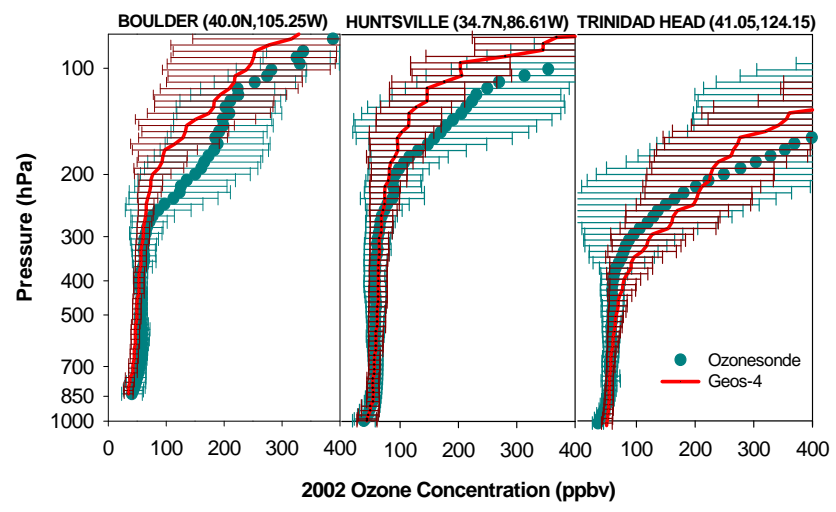

Fig. 1. Yearly variability of GEOS-Chem outputs verses ozonesonde.

2005; Streets et al., 2007; Tagaris et al., 2007; Eder and Yu, 2006). Many studies demonstrated that GEO-Chem is capable of capturing the effects from intercontinental transport of air pollutants and increasing background concentrations. (Heald et al., 2006; Liang et al., 2007; Park et al., 2003). Please note the above referenced studies may have used different versions of GEOS-Chem. For example, Heald used version 4.33 of GEOS-Chem, where as Liang et al. and Park et al. used version 7.02.

GEOS-Chem is a hybrid (stratospheric and tropospheric) 3-D global chemical transport model with coupled aerosoloxidant chemistry (Park et al., 2006). It uses 3-h assimilated meteorological data such as winds, convective mass fluxes, mixed layer depths, temperature, clouds, precipitation, and surface properties from the NASA Goddard Earth Observing System (GEOS-3 or GEOS-4) to simulate atmospheric transports and chemical balances. In this study, all GEOSChem simulations were carried out with $2^{\circ}$ latitude by $2.5^{\circ}$ longitude $\left(2^{\circ} \times 2.5^{\circ}\right)$ horizontal resolution on 48 sigma vertical layers. The lowest model levels are centered at approximately $50,200,500,1000$, and $2000 \mathrm{~m}$ above the surface. Figure $1 \mathrm{a}$ and $\mathrm{b}$ show the vertical layer structure of GEOS-Chem. The grey areas indicate the height range of tropopause in summer and winter in literature. A full-year simulation was conducted for year 2002, which was initialized on 1 September 2001 and continued for 16 months. The first four months were used to achieve proper initialization, and the following 12 months were used as the actual simulation results. All simulations were conducted using version 7.02 with GEOS-3 meteorological input. Detailed discussion of GEOS-Chem of version 7.02 is available elsewhere (Park et al., 2004).

For the purpose of developing a new algorithm for the downscaling linkage application, the outputs from GEOSChem in 2002 were being analyzed for investigating the variation of tropopause heights. Many published studies have already demonstrated the ability of GEOS-Chem to predict an ozone vertical profile using ozonesonde and satellite 


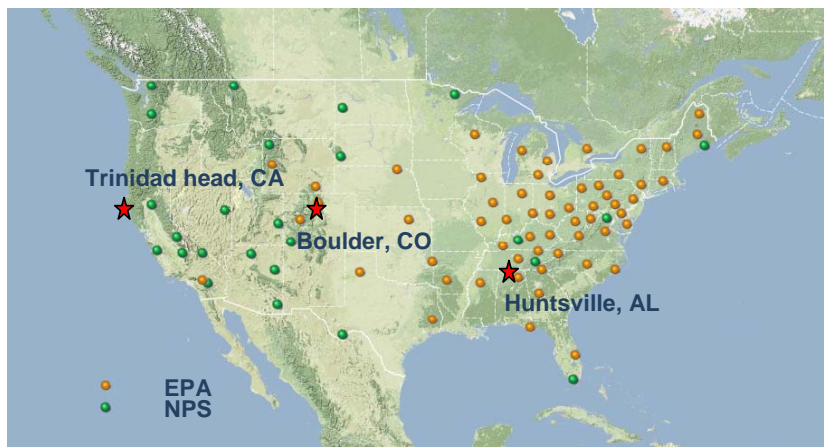

Fig. 2. The CONUS domain with observation sites marked in green or orange from CASTNET and ozonesondes in red star.

observations (Liu et al., 2006; Fusco and Logan, 2003; Martin et al., 2002), therefore, no detailed performance analysis was conducted in this study. Note that GEOS-Chem simulates stratospheric ozone with the Synoz algorithm (McLinden et al., 2000), which gives us the right cross-tropopause ozone flux but no guarantee of correct ozone concentrations in the region. That is because, until recently, crosstropopause transport of air in the GEOS fields was sometimes too fast. This is discussed for example in Bey et al., 2001; Liu et al., 2001; Fusco and Logan, 2003. Nevertheless, for this study, simple model verifications were still conducted on the GEOS-Chem outputs using available ozonesonde data in the USA (Newchurch et al., 2003) Particular interest was given to upper troposphere and tropopause regions $(1000 \mathrm{hPa}$ to $50 \mathrm{hPa}$ ), where the downscaling process could be influenced by stratospheric ozone. Figure 2 shows the yearly variability of GEOS-Chem with ozonesonde data. It is observed that $99.5 \%$ of GEOS-Chem outputs are contained within the statistical range of the observation data, which gives a good indication of reasonable model results. For the Boulder and Huntsville sites, good model performances were found at higher pressure when the pressure fell between $1000 \mathrm{hPa}$ to $300 \mathrm{hPa}$. Consistent under-predictions were observed at the upper atmosphere when the pressures dropped below $250 \mathrm{hPa}$.

\section{MM5 and CMAQ}

The CMAQ meteorological inputs are driven by NCAR's 5th generation Mesoscale Model version 3.7. (MM5) with hourly temporal resolution, $36 \mathrm{~km}$ horizontal resolution, and 34 sigma vertical layers. All MM5 simulations were conducted using the one-way nested approach from $108 \mathrm{~km}$ over North America (140-40 W, 10-60 N) down to $36 \mathrm{~km}$ continental US (128-55 W, 21-50 N). For meteorological initial and boundary conditions, the NCEP Final Global Analyses (FNL) data (i.e., ds083.2) with resolution of $1^{\circ}$ by $1^{\circ}$ from the US National Centers for Environmental Predic-

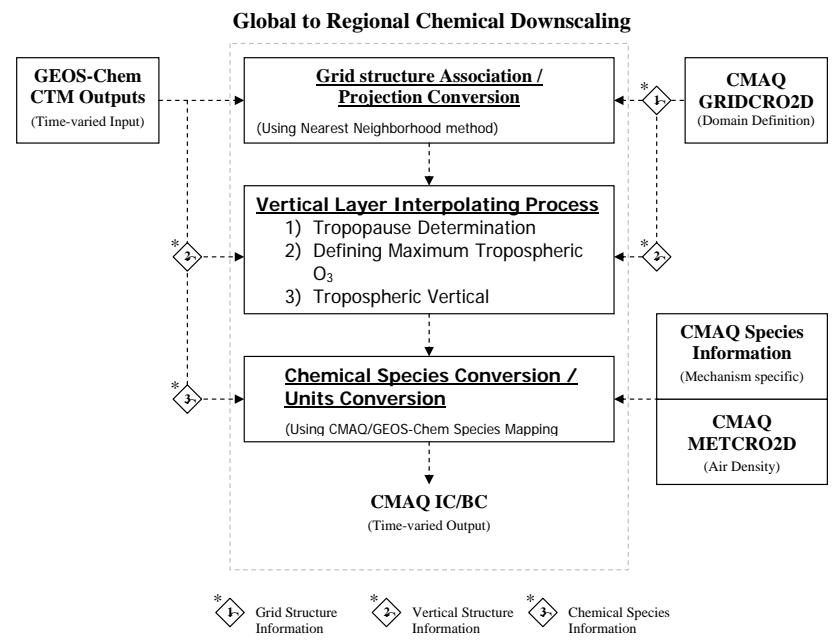

Fig. 3. Systematic flowchart of global to regional chemical downscaling.

tion (NCEP) was used. For MM5 simulations, 4-D analysis nudging technique was employed to reproduce the observed weather conditions using the surface and upper layers observations from DS353.4 and DS464.0, respectively. The new Kain-Fritsch cumulus, Mix-phase micro-physic, RRTM long-wave radiations, planetary boundary layer (PBL) and land surface model (LSM) were configured in the simulations. A detailed summary of MM5 configuration is listed in Table 1. For CMAQ, Lambert conformal projection with true latitude limits of 25 and 40 was used on 148 by 112 grid cells with horizontal resolution of $36 \mathrm{~km}$. A total of 19 sigma vertical layers were extracted from MM5. The lowest model levels were centered at approximately 20, 50, 90, $130,180,250,330$, and $400 \mathrm{~m}$ above the surface as shown in Fig. 1a and b. The center of the horizontal domain was set at $100 \mathrm{~W}$ and $40 \mathrm{~N}$. This domain covers the entire continental US with part of the Mexico and Canada (referred to as CONUS domain), which is shown in Fig. 3. In CMAQ simulations, three scenarios with different lateral boundary conditions were performed, which included profile boundary conditions (Profile-BC), ordinary vertical interpolated GEOSChem boundary conditions (ORDY-BC), and vertical interpolated GEOS-Chem boundary conditions using the new algorithm (Tropo-BC). All of these simulations were configured with Carbon Bond IV (CB-IV) chemical mechanism with aerosol module (AERO3). The detailed configuration is also shown in Table 1.

\section{Linkage methodology between GEOS-Chem and CMAQ}

The GEOS-Chem outputs were extracted as CMAQ lateral boundary conditions using GEOS2CMAQ linkage tool, which involved grid structure association, horizontal/vertical 

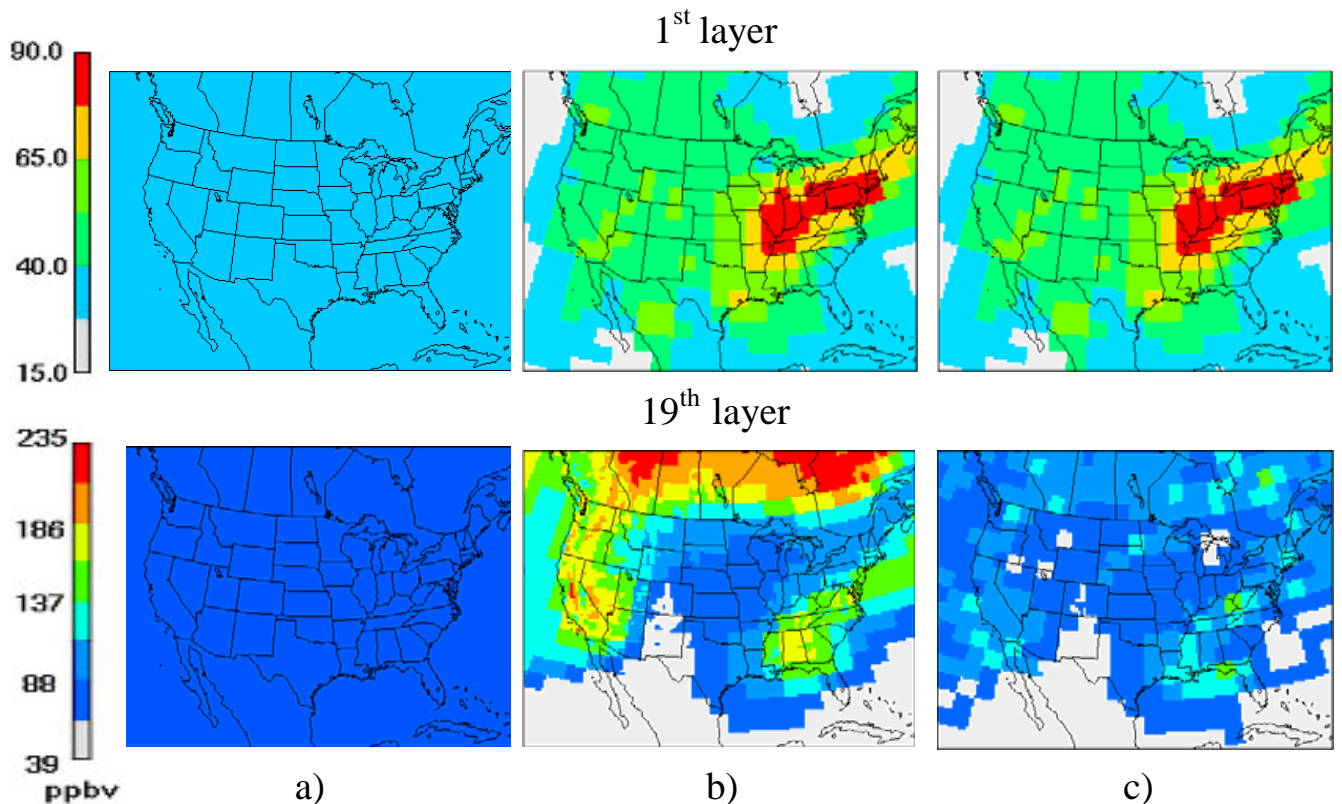

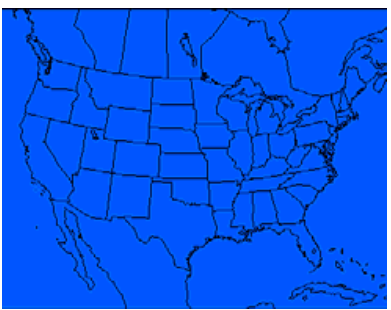

a)

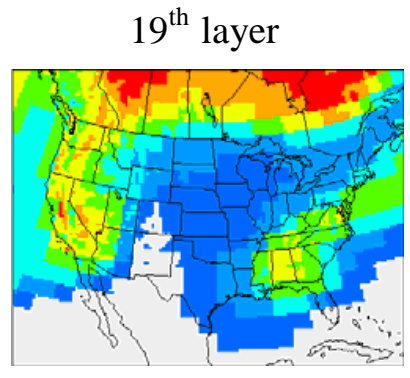

b)

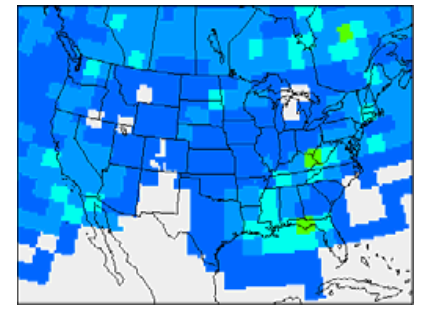

c)

Fig. 4. Comparison of different lateral boundary conditions in 1st and 19th layers, (a) Profile-BC, (b) ORDY-BC, and (c) Tropo-BC.

Table 1. MM5 and CMAQ Model Configurations for 2002 simulations.

\begin{tabular}{ll}
\hline & MM5 Configuration \\
\hline Model version & 3.7 \\
Number of sigma level & 34 \\
Number of grid & $156 \times 120$ \\
Horizontal resolution & $36 \mathrm{~km}$ \\
Map projection & Lambert conformal \\
FDDA & Analysis nudging \\
Cumulus & Kain-Fritsch 2 \\
Microphysics & Mix-phase \\
Radiation & RRTM \\
PBL & Pleim-Xiu \\
LSM & Pleim-Xiu LSM \\
LULC & USGS 25-Category \\
\hline & CMAQ Configuration \\
\hline Model version & 4.5 \\
Number of Layer & 19 \\
Number of grid & $148 \times 112$ \\
Horizontal resolution & 36 km \\
Horizontal advection & PPM \\
Vertical advection & PPM \\
Aerosol module & AERO3 \\
Aqueous module & CB-IV \\
Emission & VISTAS emissions (NEI 2002 G) \\
Boundary condition I & CMAQ Predefined Vertical Profile \\
Boundary condition II & 2002 GEOS-Chem \\
\hline
\end{tabular}

www.atmos-chem-phys.net/9/9169/2009/ interpolation, and chemical mapping processes. A summary of the systematic flowchart of the linkage methodology is shown in Fig. 4. It should be noted that most of the regional models including CMAQ do not utilize top boundary condition as input. As a result, in this study, no top boundary condition is generated. In the linkage process, GEOS2CMAQ applied the "nearest neighbor" method to associating the latitude/longitude formatted GEOS-Chem outputs with the CMAQ Lambert Conformal gridded format. Horizontal interpolating process then utilized the results to interpolate the GEOS-Chem outputs into CMAQ gridded format for each vertical layer column. For Tropo-BC, a newly developed tropopause-determining algorithm, which is based on chemical $\left(\mathrm{O}_{3}\right)$ tropopause definition, was implemented in the vertical interpolating process to identify the tropopause height. Moreover, it separated the troposphere from the stratosphere for each horizontal grid. Different interpolating processes were employed in the tropospheric and the stratospheric regions. A detailed discussion may be found in the latter section of this document. For the chemical mapping process, 37 GEOS-Chem species were transformed into $30 \mathrm{CB}$ IV mechanism species of CMAQ according to the chemical definitions given in Appendix A. The GEOS-Chem species with the same definitions as CB-IV species were mapped directly into CMAQ; where as other species were mapped by partitioning and/or regrouping processes. For example, total oxidants $\mathrm{O}_{\mathrm{x}}$ species in GEOS-Chem were defined as the combination of $\mathrm{O}_{3}$ and $\mathrm{NO}_{\mathrm{x}}$. Therefore, to obtain $\mathrm{O}_{3}$ concentrations, $\mathrm{O}_{\mathrm{x}}$ was subtracted by $\mathrm{NO}_{\mathrm{x}}$ species in the GEOS-Chem. Other species, such as paraffin carbon bond (PAR), were composed of multiple species in GEOS-Chem. 
Regrouping was required to reconstruct the CB-IV corresponding species, which is shown as follows:

$\mathrm{PAR}=$

$\frac{1}{4} \mathrm{ALK} 4+\frac{1}{3} \mathrm{C}_{3} \mathrm{H}_{8}+\frac{10}{4} \mathrm{C}_{2} \mathrm{H}_{6}+\frac{1}{3} \mathrm{ACET}+\frac{1}{4} \mathrm{MEK}+\frac{1}{2} \mathrm{PREPE}$

For chemicals that were not supported by GEOS-Chem, CMAQ predefined boundary conditions were used to maintain the full list of CMAQ CB-IV species.

\section{Tropopause determining algorithm}

The newly developed tropopause-determining algorithm was added to the ordinary interpolating process (i.e., uses pressure level as the only criteria in the interpolating process) for handling the near tropopause and stratosphere interpolating processes, which is essential to correct and represent the global model outputs in the regional model. We have utilized the chemical/ozone tropopause definition described in Bethan (1996), instead of thermal and dynamic tropopause definitions, as the basis for separating the stratosphere and the troposphere. Although thermal and dynamic tropopauses are more commonly used in determining the tropopause, we have identified that these tropopauses are inappropriate for this application because of the observed stratospheric ozone effect at the troposphere. Since the purpose of determining tropopause is to exclude stratospheric pollutants concentrations from the global model during the interpolating process, ozone tropopause is better suited for this application. Ozone tropopause is defined as the location at which an abrupt change of ozone concentration occurred. Our algorithm finds the ozone tropopause by finding the largest negative rate of change of slope (i.e., could be negative) from the plot of elevation verses ozone concentration. In other words, we have taken the second derivative of elevation with respect to ozone concentration and found the lowest value.

$\mathrm{H}_{\operatorname{Tropo}\left(C_{i}\right)}=\max \left|\frac{C_{i+1}-C_{i}}{\mathrm{H}_{i+1}-\mathrm{H}_{i}}-\frac{C_{i}-C_{i-1}}{\mathrm{H}_{i}-\mathrm{H}_{i-1}}\right|$

where $8 \mathrm{~km}<\mathrm{H}<19 \mathrm{~km}$

Each rate of change of slope requires 3 data points or 2 line segments, upon which two line slopes were calculated. In the tropopause level, which is indicated by the largest negative rate of change of slope, a combination of a small concentration change in the first segment with a large concentration change in the second segment were obtained. Occasionally, a false tropopause was identified when an extremely small change of ozone concentration in the first segment or negative change of ozone concentrations in the second segment occurred. To ensure the tropopause found by this method is a reasonable tropopause height with no stratospheric effect, we have cross checked the tropopause results with thermal tropopause heights (i.e., ozone tropopause should be lower than thermal tropopause), as well as the maximum concentrations of ozone should exceed $300 \mathrm{ppbv}$ as found in the literature. (McPeters et al., 2007).

For the vertical interpolating process in GEOS2CMAQ, stratospheric ozone is excluded by limiting the maximum ozone concentration at the tropopause level while generating CMAQ lateral boundary conditions. Unlike some of the studies, without enforcing any upper bound limit or using predefined maximum ozone concentration, we have dynamically determined the altitude of the tropopause for each grid and time-step in GEOS-Chem outputs for use in the vertical interpolating process (Morris et al., 2006; Song et al., 2008; Tang et al., 2007).

\section{Results and discussion}

\subsection{CMAQ lateral boundary conditions}

We have generated CMAQ lateral boundary conditions from every third hour GEOS-Chem output for VISTAS CMAQ simulation using GEOS2CMAQ linkage tool. Figure 5 shows the vertical ozone profiles from GEOS-Chem with CMAQ vertical layers for both summer and winter. It should be noted that the tropopause in summer is much higher than the tropopause in winter. As a result, less stratospheric ozone is included in summer than winter when the vertical interpolating process is performed. In Fig. 6, comparisons of Profile-BC, ORDY-BC, and Tropo-BC for 22 June 2002 is shown on the CONUS domain. The top row represents the 1st CMAQ layer ( $\sim 1000$ millibars) and the bottom shows the top CMAQ layer (i.e., 19th layer 140 millibars). These plots are intended to demonstrate the horizontal distribution of ozone concentrations across the CONUS domain. The Profile-BC was designed to represent the relatively clean air conditions for the CONUS boundaries. It enforces a pre-defined vertical profile with no temporal and spatial dependencies. In general, the surface ozone concentrations (i.e., 1st layer) range between 30 to $35 \mathrm{ppbv}$ and they progressively increase and reache a peak ozone concentration of $70 \mathrm{ppbv}$ at the top (i.e., 19th layer). The ORDY$\mathrm{BC}$ and Tropo-BC were both generated using the linkage methodology described earlier. This methodology intends to incorporate the effects of intercontinental transport of air pollutants and the rise in background ozone concentrations into CMAQ by utilizing GEOS-Chem outputs. (Bertschi et al., 2004; Fiore et al., 2003; Park et al., 2004) The temporal and horizontal variations in GEOS-Chem were captured into CMAQ to reflect daily diurnal differences in concentrations. In ORDY-BC and Tropo-BC, the difference was the vertical interpolating process. ORDY-BC uses the ordinary vertical interpolating process, where as Tropo-BC uses the 

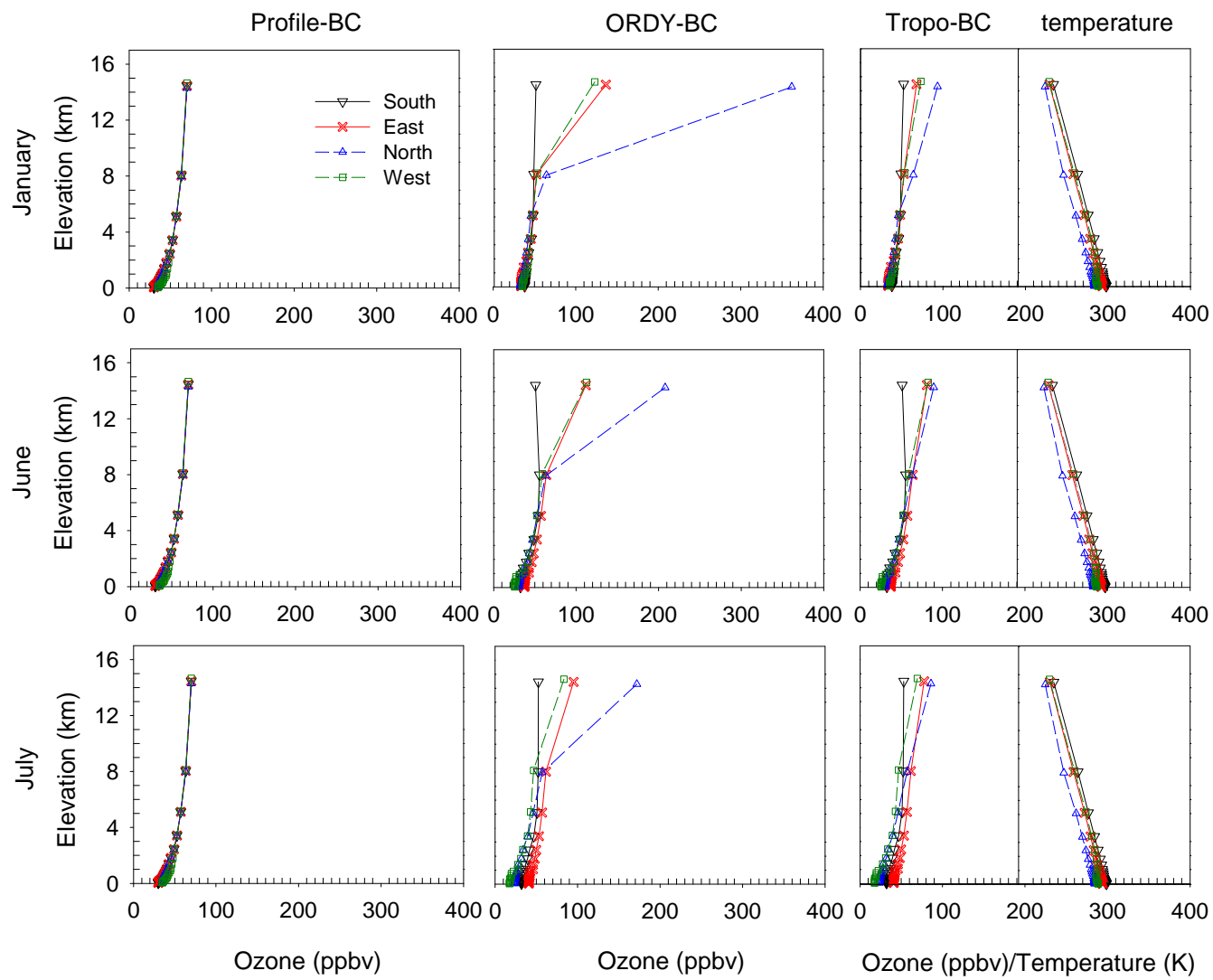

Fig. 5. Monthly vertical distribution of ozone from CMAQ BCs: South (black line), East (Red line), North (blue line), and West (green line) of CONUS domain in January, June and July with temperature profiles for Profile-BC (left), ORDY-BC (middle) and Tropo-BC (right).

ordinary vertical interpolating process with the tropopausedetermining algorithm that excludes pollutants in the stratosphere from the interpolating process. In the surface level (1st layer), both ORDY-BC and Tropo-BC perform identically; ozone concentrations ranged from $19 \mathrm{ppbv}$ to $90 \mathrm{ppbv}$ depending on location and time on June 22nd. For other days in 2002 (i.e., January, June, and July), ozone concentration could reach up to $130 \mathrm{ppbv}$ at the surface. In the top level (1 th $^{\text {th }}$ layer), the ORDY-BC ozone reaches as much as $235 \mathrm{ppbv}$ and the Tropo-BC ozone achieves up to $160 \mathrm{ppbv}$ in the CONUS domain on 22nd June. For other days in 2002, the ORDY-BC and Tropo-BC ozone reaches up to $714 \mathrm{ppbv}$ and $205 \mathrm{ppbv}$, respectively. In Considine (2008), the reported maximum mean tropopause ozone concentration from observations in North America is about 235 ppbv based on the thermal tropopause definition. We would have expected that if Considine's analyses used the ozone tropopause as its definition, the maximum tropopause ozone concentrations should be lower since the ozone tropopause is constantly lower than the thermal tropopause at the upper troposphere. So, the maximum ORDY-BC ozone of $714 \mathrm{ppbv}$ would be too high in the troposphere and would impractically bring high ozone to surface level, where as the maximum Tropo$\mathrm{BC}$ ozone of $205 \mathrm{ppbv}$ has fallen within a reasonable value in the United States. It should be noted that the Considine's data is concentration at higher latitudinal locations. With the direct proportional relationship between latitudinal location and tropopause ozone concentration, we would expect that the reported $235 \mathrm{ppbv}$ should be a high end of the ozone concentration at the tropopause in the United States.

As tests of the lateral boundary conditions' responses to the GEOS2CMAQ linkage tool, we have extracted the vertical profiles of various CMAQ boundary conditions for selected months to investigate the seasonal effects of the data. Figure 7 shows average monthly ozone vertical distribution from all four boundaries of the CONUS domain: East, West, South, and North are shown in various colors with average vertical temperature profiles for January, June, and July. January represents the winter condition where tropopause is relatively low as a consequence of cold temperatures; July characterizes the summer condition with possible high surface ozone concentration. The additional month of June is selected because we have occasionally observed high effects of stratospheric ozone to the surface ozone from the MISCASIA study (Fu et al., 2008). As expected, Profile-BC on the left has shown no seasonal variation. In contrast, the ORDY-BC and Tropo-BC are both showing a seasonal dependence. The ORDY-BC in the middle panel has shown a 

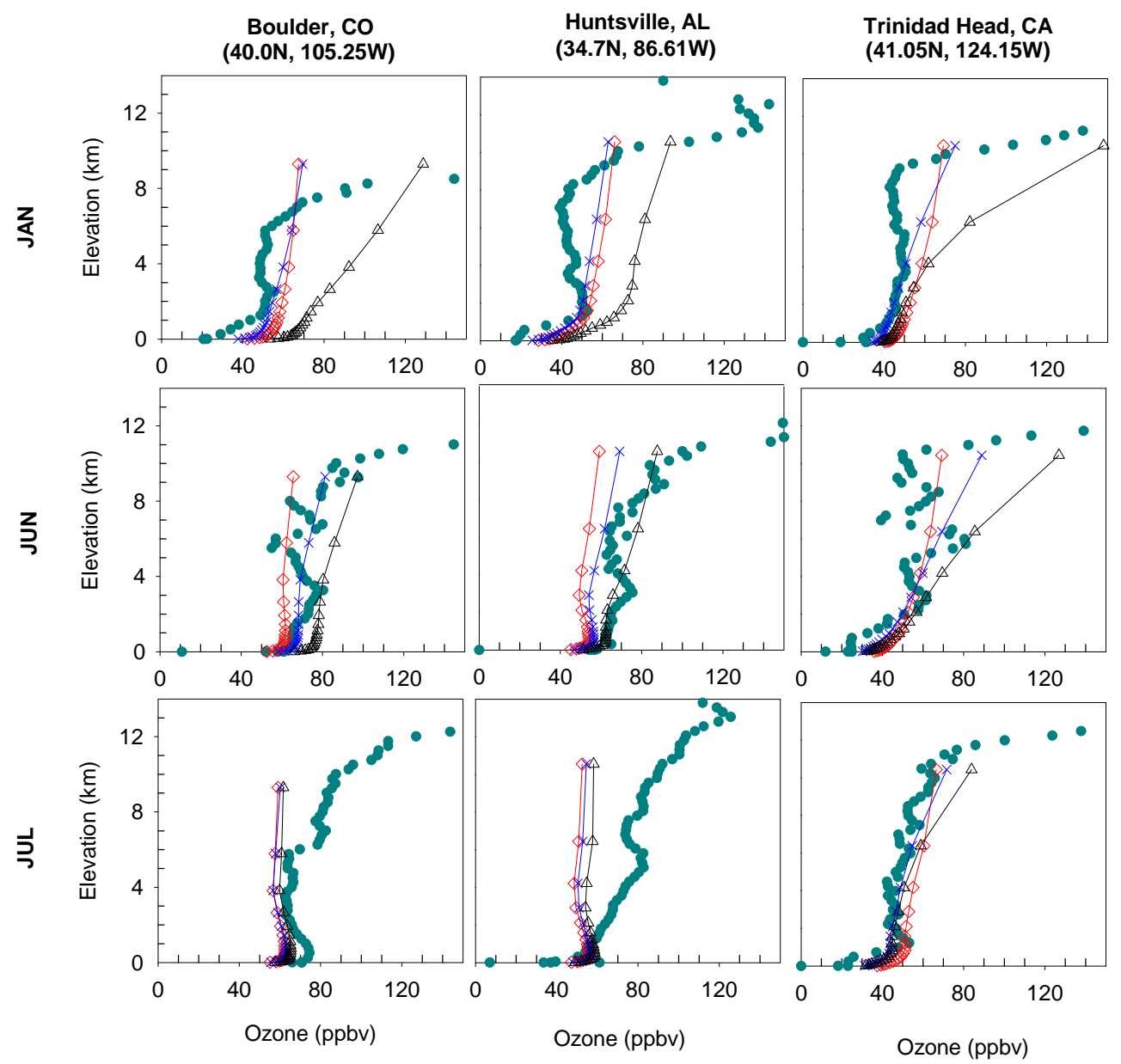

- Ozonesonde $\diamond$ Profile-BC $\rightarrow$ Tropo-BC $\triangle$ ORDY-BC

Fig. 6. CMAQ simulated monthly vertical distribution of ozone for Profile-BC (red line), Tropo-BC (blue line) and ORDY-BC (black line) with ozonesonde.

strong seasonal difference at the top CMAQ layer (i.e., blue line). This dependence directly relates to the seasonal difference in ozone tropopause heights as a result of temperature differences. In the ORDY-BC interpolating process, the amount of stratospheric ozone included in boundary conditions is governed by the altitude of ozone tropopause. It is highly sensitive with elevation because ozone is exponentially increased with altitude beyond tropopause or at stratosphere. The vertical structures of CMAQ and GEOS-Chem are also playing an important role. With the constant elevations in CMAQ layers, the higher the tropopause is located, the less stratospheric effect will result. As shown in Fig. 7, the monthly average ozone concentrations for ORDY-BC on North bound at the top CMAQ layer for January, June, and July are 362 ppbv, 207 ppbv, and 172 ppbv, respectively. As recalled from early comparisons with Considine (2008), this average concentration in January is too high. For Tropo-BC, shown on the right panel, little seasonal variation is observed at the top CMAQ layer. The average monthly ozone concen- trations of $94 \mathrm{ppbv}, 90 \mathrm{ppbv}$, and $86 \mathrm{ppbv}$ are found on the North bound for January, June, and July, respectively. These results demonstrate the effects of tropopause-determining algorithm, which have limited the stratospheric effects from the BCs.

In addition to the seasonal effect, latitudinal effect is also observed in Fig. 7, where South bound (i.e., downward triangle in black) has the lowest concentration and the North bound (i.e., upward triangle in blue) exhibits the highest concentration at the upper CMAQ layers (top two layers) on both ORDY-BC and Tropo-BC. The latitudinal effect is mainly induced by the temperature differences at troposphere on different boundaries. The vertical temperature profile in CMAQ on the right shows a decrease in temperature with increase in elevation; no temperature inversion is observed. This indicates all CMAQ layers have fallen within the troposphere because it illustrates a tropospheric laps rate pattern. 
a)

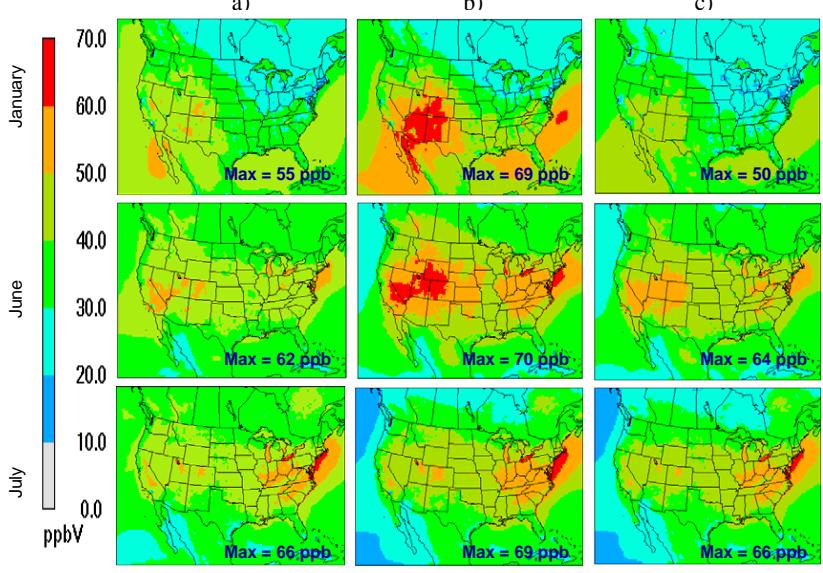

Fig. 7. Comparisons of monthly average ozone concentrations in January, June and July from CMAQ outputs; a) Profile-BC (left), b) ORDY-BC (middle), and c) Tropo-BC (right). The maximum concentration within the domain is shown at the bottom of right hand corner.

\subsection{CMAQ outputs}

The CMAQ model was used to simulate the surface ozone concentrations in $36 \mathrm{~km}$ CONUS domain using Profile-BC, ORDY-BC and Tropo-BC with VISTAS emissions inventories (Morris et al., 2006). Figure 8 shows the CMAQ simulated vertical distribution of monthly ozone in Boulder, CO, Huntsville, AL, and Trinidad head, CA with available ozonesonde for the months of January, June, and July. In the plot, the elevation is taken from the mid-point of each CMAQ layer. It should be noted that CMAQ is a tropospheric model. Therefore, the maximum concentration of ozone should not exceed the reported maximum tropopause concentration of 235 ppbv. It is observed that ORDY-BC (i.e., in the black triangle) overestimates the January ozone concentrations for all locations in all altitudes (i.e., top panels). Moreover, overestimations are also observed in June at Boulder (i.e., middle left panel) and Trinidad Head at upper altitude (i.e., middle right panel). The overestimations in ORDY-BC mainly resulted from bad lateral boundary conditions (i.e., unreasonable ozone concentration at the troposphere) propagated through the downscaling process. By removing stratospheric ozone from ORDY-BC, which is demonstrated by Tropo$\mathrm{BC}$, CMAQ outputs have shown a much better result when compared with ozonesonde. For Profile-BC, similar results as Tropo-BC are observed; slight extra overestimations are found in January and slight extra underestimations are found in June and July when compared with Tropo-BC. Overall, Tropo-BC shows the best agreement with ozonesonde data. It should be noted that the underestimations in Huntsville in July are unrelated to the selection of lateral BCs since very little differences are observed among different lateral BCs. The underestimations in here demonstrate once again that the CMAQ model is incapable of simulating the upper ozone concentration in the area where a large change of upper ozone concentration occurred. We believe that this may be resolved if CMAQ can implement the STE mechanism along with supplementary upper boundary condition from GCM.

Figures 9 and 10, respectively, show the outputs of the average monthly surface ozone concentrations and the maximum monthly surface ozone concentrations for January (top frames), June (middle frames), and July (bottom frames). The maximum ozone concentrations within the domain are also listed at the corner and denoted in blue or white. In Fig. 9, the output results show that similar ozone concentration patterns are found across the CONUS domain among all three BCs with some exceptional high ozone being observed in the ORDY-BC. It is believed that these high ozone concentrations occurring in the Western United States in ORDY-BC are the consequence of high ozone observed at the top layer of CMAQ boundaries discussed earlier. The undesirable boundary conditions (i.e., ORDY-BC) produce abnormal surface ozone concentrations for both January and June. Since ozone is a photochemical pollutant driven by NOx, VOCs, and temperature, we would expect higher monthly average ozone should be observed in July rather than in January. In the top frames, the reported maximum average ozone concentrations in January for Profile-BC, ORDY-BC, and Tropo$\mathrm{BC}$ are $55 \mathrm{ppbv}, 69 \mathrm{ppbv}$, and $50 \mathrm{ppbv}$, respectively. A similar trend is observed for June. For July (bottom frames), the effects of stratospheric ozone in ORDY-BC become minimal due to the fact that the tropopause is much higher than other months at the top layer. As a result, fewer differences are found among these three scenarios. Figure 10 shows that the monthly maximum 8-h ozone concentration in January on ORDY-BC is in excess of $150 \mathrm{ppbv}$ over the western United States. The result indicates that the effect of stratospheric ozone in lateral boundary conditions has a significant impact on surface ozone concentrations, as a result of the high ozone aloft mixing downward quickly. The large differences observed between ORDY-BC and Profile-BC/Tropo-BC reveal an important message, which is "excluding stratospheric ozone on tropospheric model during the downscaling process is extremely important. We have found the concentration differences between these scenarios could be as much as $87 \mathrm{ppbv}$ in January. These differences gradually decrease with temperature increasing through June and July. The effects of lateral BCs in ORDY-BC have contributed to the high surface concentrations observed in the western United States in January and June. Since both ORDY-BC and Tropo-BC utilize a dynamic algorithm to interpolate the vertical ozone profile for each horizontal grid for lateral BCs, the variations in the western boundary are observed primarily due to the treatments of stratospheric ozone. Note that the Tropo-BC is intended to demonstrate the effectiveness of the tropopausedetermining algorithm of separating the stratospheric and tropospheric ozone for the lateral boundary condition. 
a)
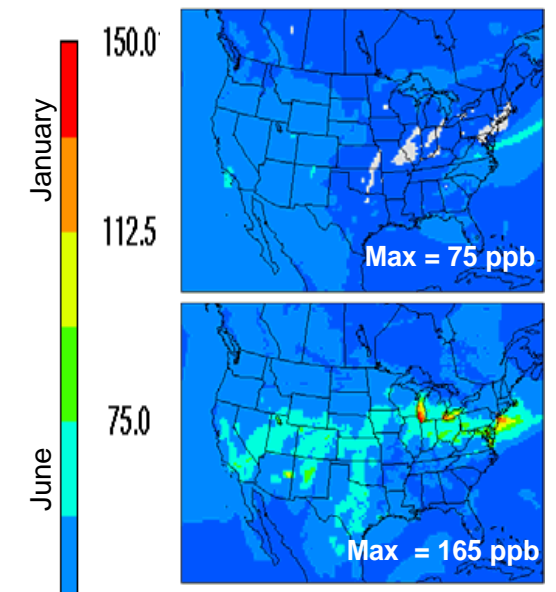

ב๊̀ 0.0 b)
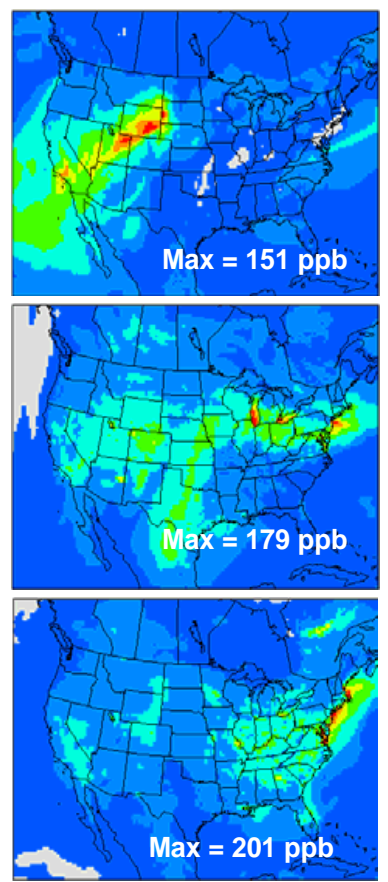

C)
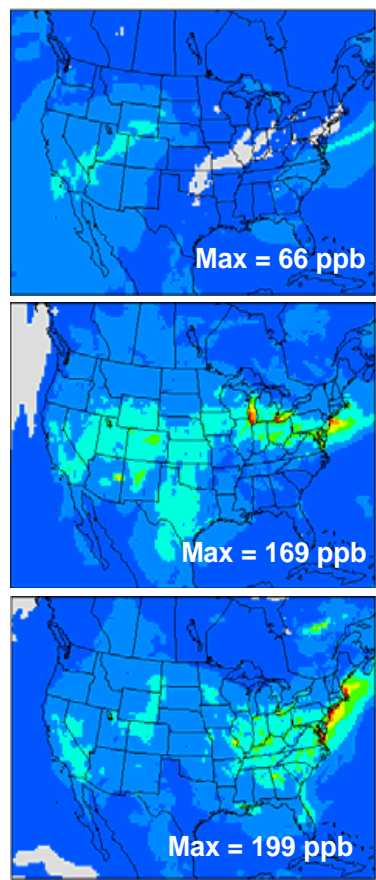

Fig. 8. Comparisons of monthly maximum 8-h surface ozone concentrations in January, June and July from CMAQ outputs; (a) Profile-BC (left), (b) ORDY-BC (middle), and (c) Tropo-BC (right). The maximum concentration within the domain is shown at the bottom of right hand corner.

\subsection{CMAQ performance analyses}

Model performance analyses on all three cases have been performed using the entire CASTNET dataset, in which 70+ observation sites across the CONUS domain from both EPA and the National Park Service (NPS) are included. It should be noted that our study only simulates the $36 \mathrm{~km}$ domain and it is intended to demonstrate the effects of different BCs. Hence, the results in root mean square error in this research may be higher than the one in a finer resolution CMAQ. Figure 11 shows the simulated and measured surface ozone for the months of January, June, and July at the nearest locations of the ozonesonde sites found in CASTNET network (see Fig. 3 denoted in red star). In the plot, blue, purple, green, and red colors correspond to observation, Profile-BC, ORDY-BC, and Tropo-BC, respectively. And the top, middle, and bottom panels show the first 15 day's outputs for January, June, and July, respectively. It should be noted that, due to limitation of the size of the plot, we have only documented the first 15 days of data in Fig. 11. However, our analyses are based on a full month of data. The quoted number below each point represents root mean square error (RMSE) for each case, with the same color scheme used on the plot.

\subsubsection{ORDY-BC}

In these time series plots, we, once again, found the surface ozone in ORDY-BC is over predicted in January and June (i.e., top and middle panels) and it is in agreement with our results early in Fig. 10. In comparisons of RMSE, ORDY-BC has shown the worst prediction of surface ozone comparing with others. The RMSE reaches as much as 23.0 ppbv. The highest RMSE occurs at the conditions where the tropopause is low in January and at "near Boulder" site (top left panel). This large RMSE strongly ties to the parameters such as air temperature, altitudinal, and latitudinal locations. Since "near Boulder" is located much higher in altitude (i.e., Boulder at about $1650 \mathrm{~m}$ above mean sea level) than Huntsville and Trinidad head, the larger amount and quicker downshift of uncontrolled stratospheric ozone is expected at the surface of ORDY-BC. This did not happen in Profile-BC and Tropo-BC since both of them do not contain any stratospheric ozone. For air temperature, January has much lower air temperature than June and July. With the relationship of air temperature, it is directly proportional to tropopause height; lower air temperature means a lower tropopause height. Therefore, a larger amount of aloft ozone is included in the lateral boundary condition of ORDY-BC and results from a huge over prediction of surface ozone in "near Boulder". This low temperature effect has also 


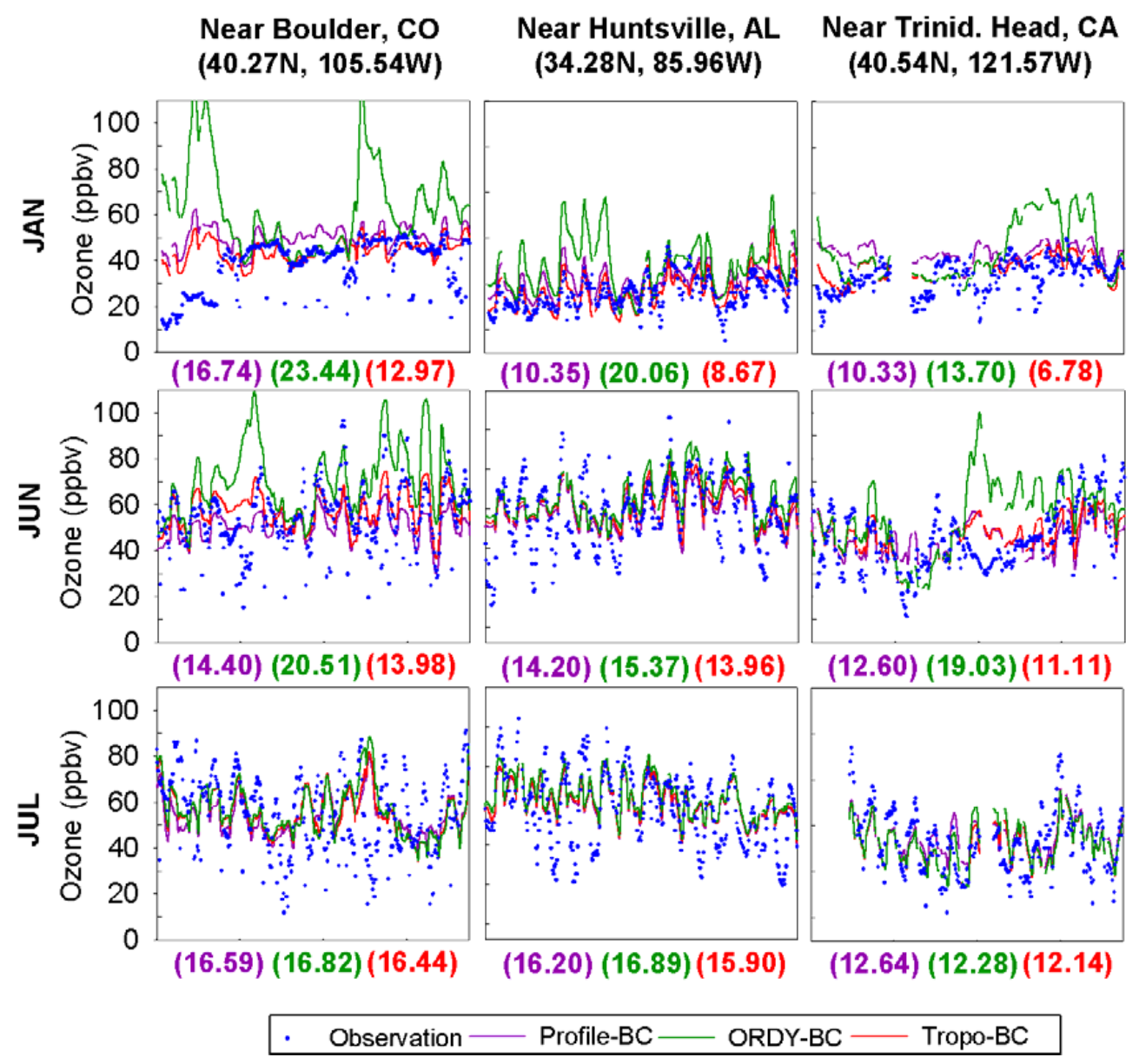

Fig. 9. Comparison of simulated and measured surface ozone concentration for month of January, June and July from the selected sites. The quoted value at the bottom of each plot revives the root mean square error of each case.

a)

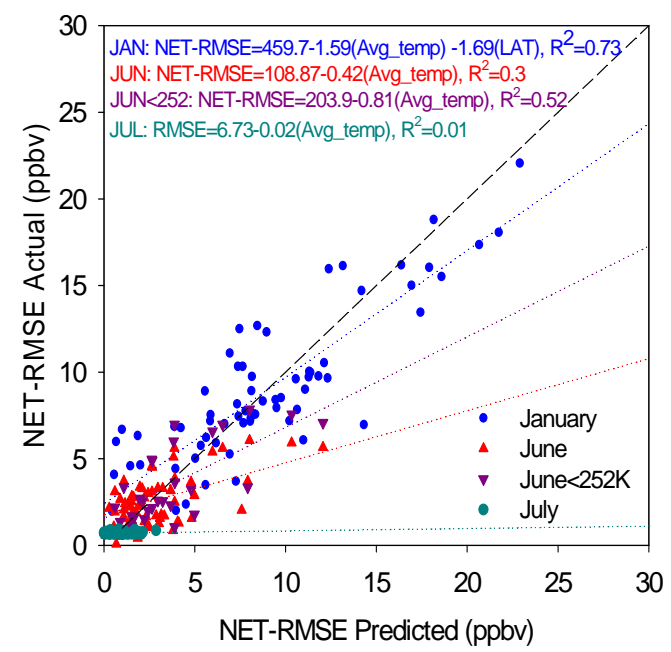

b)

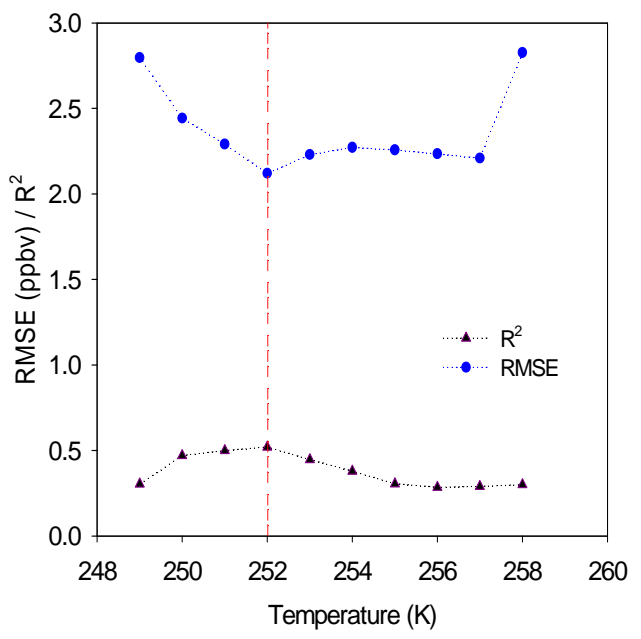

Fig. 10. Statistical analysis outputs from CASTNET sites: (a) NET-RMSE actual vs. NET-RMSE predicted, (b) sensitivity analysis on best-fit equation for June data. 
Table 2. Summary of NET-RMSE and average column temperatures for the sonde sites.

\begin{tabular}{llll}
\hline & Boulder, CO & Huntsville, AL & Trinidad head, CA \\
\hline JANUARY & Tc $=236 \mathrm{~K}$ & Tc $=246 \mathrm{~K}$ & Tc $=242 \mathrm{~K}$ \\
& NET-RMSE $=10.5 \mathrm{ppbv}$ & NET-RMSE $=11.4 \mathrm{ppbv}$ & NET-RMSE $=6.9 \mathrm{ppbv}$ \\
JUNE & Tc $=247 \mathrm{~K}$ & Tc $=254 \mathrm{~K}$ & Tc $=252 \mathrm{~K}$ \\
& NET-RMSE $=6.5 \mathrm{ppbv}$ & NET-RMSE $=1.4 \mathrm{ppbv}$ & NET-RMSE $=7.9 \mathrm{ppbv}$ \\
JULY & Tc $=253 \mathrm{~K}$ & Tc $=257 \mathrm{~K}$ & Tc $=255 \mathrm{~K}$ \\
& NET-RMSE $=0.39 \mathrm{ppbv}$ & NET-RMSE $=1.0 \mathrm{ppbv}$ & NET-RMSE $=0.1 \mathrm{ppbv}$ \\
\hline
\end{tabular}

Tc is average vertical column temperature; NET-RMSE is the RMSE differences between Profile-BC and Tropo-BC.

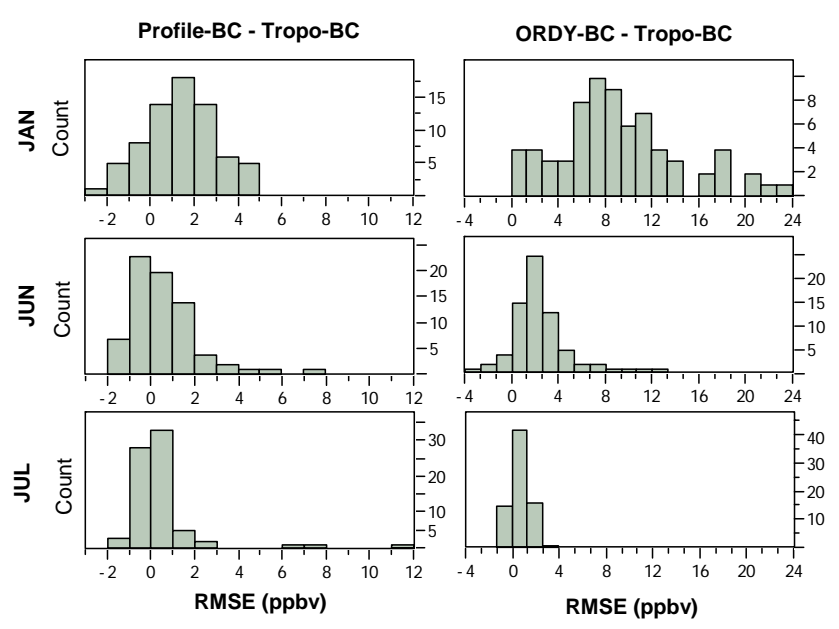

Fig. 11. Summary of the RMSE distributions for the differences among these three scenarios for each CASTNET sites.

contributed to the high RMSE found in "near Huntsville" and "near Trinidad head" sites in January.

Another high RMSE(s) is found in "near Boulder" and "near Trinidad head" in June. These high RMSE(s) most likely relate to the low tropopause height resulting from low air temperature. We believe latitudinal location might explain why "near Boulder" and "near Trinidad head" observed high RMSE, where as "near Huntsville" did not. In general, the higher latitudinal location is, the lower temperature will be when it is further away from the equator. The low temperature condition affects the downscaling process by changing the tropopause height and resulting in more stratospheric ozone in the lateral boundary conditions in ORDYBC. To demonstrate the effect of tropopause due to air temperature and latitudinal location, we calculated the RMSE in all CASTNET sites for each boundary condition. Moreover, we subtracted the RSME in ORDY-BC to the RSME in Tropo-BC to yield a net RSME to account for stratospheric ozone effect, denoted as NET-RSME. Note that the difference between ORDY-BC and Tropo-BC is the extra stratospheric concentrations from GEOS-Chem. Therefore, we use the differences in RMSE as an indicator for stratospheric effects on surface ozone performance. Multivariate statistical fitting is performed on NET-RMSE with monthly average column temperature and latitudinal location. Fig. 12 shows the results from statistical analyses: (a) multivariate fitting for NET-RMSE on each month, (b) sensitivity analysis on multivariate fitting for the month of June. Note that the equations on top of Fig. 12a are the best-fit equations for temperature and latitude. These equations are used to generate the NET-RMSE predicted in Fig. 12 (a) and they do not represent the best-fit equations for the straight lines shown in Fig. 12a. For January, NET-RMSE is highly correlated with latitudinal location and air temperature with $R^{2}$ of 0.73 and RMSE of 2.73. For June, only air temperature is correlated to NET-RMSE with $R^{2}$ of 0.3 . And for July, no correlation is found on either latitudinal location or air temperature. Since NET-RMSE is an indicator of the stratospheric effect from the lateral BCs, we believed that no correlation observed in July implies the average column air temperature has reached a certain level at which tropopause height is higher than the upper boundary of CMAQ. Thus, no stratospheric ozone is included in the lateral BCs. To determine the temperature at which there is no stratospheric effect, we have performed sensitive fittings on June's data because it contains both stratospheric effect sites and nonstratospheric effect sites. Figure $12 b$ shows the results of the sensitive test and the observed break point temperature is about $252 \mathrm{~K}$, at which the lowest RMSE and the highest $R^{2}$ are obtained. These results are consistent with our early explanations of why bad predictions of ORDY-BC occurred in January and June and similar predictions as Tropo-BC are found in July. Table 2 shows the monthly average column temperature along with NET-RMSE in all three ozonesonde sites for all months. For January, all three sites have the average temperature lower than $252 \mathrm{~K}$. Therefore, a large NETRMSE caused from stratospheric ozone is expected. For June, Boulder and Trinidad head are equal or below $252 \mathrm{~K}$, where as Huntsville is above $252 \mathrm{~K}$. Hence, a large NETRMSE(s) is observed in those two sites and a small NETRMSE is found in Huntsville. These results are in agreement with our conclusions made earlier on the time-series plots 
in Fig. 11. Overall, these results stress the important relationship of temperature and seasonal changes in the GCM downscaling process.

\subsubsection{Profile-BC}

For Profile-BC versus lateral boundary conditions from GCTM, Tang et al. (2007, 2009), have found that the performance of boundary conditions from GCTM may not necessarily be better than Profile-BC. Moreover, different GCTM outputs also yield different results. The performance of lateral boundary conditions from GTCM (GCTM-LBC) highly depends on locations and scenarios of the GCTM-LBC, also the type of GCTM used. Al-Saadi et al. (2007), suggested that this phenomenon might relate to the ozone aloft in GCTM-LBC, where rapid transports of stratospheric ozone into the surface level are observed. In addition, they have found that GCTM-LBC enhances the model errors of ozone concentration at the surface in the range of 6 to $20 \mathrm{ppbv}$ in Trinidad Head in August. Since these studies have selected the summer ozone season (i.e., August) as their study period, we expected that the effect of stratospheric ozone would be minimal based on the relationship we developed earlier. However, this did not happen. In this case, we suspect their average column temperature in August for Trinidad head may not be hot enough to exclude the stratospheric ozone from the GCTM-LBC interpolating process, or it may be affected by the quality of GCTM-LBC as inputs where strong boundary influx of ozone affects the simulation results. Nevertheless, these studies have indicated that GCTMLBC preprocessing may be required. In our study, we have implemented the tropopause-determining algorithm, which is based on chemical tropopause definition, as the preprocessor for generating ORDY-BC and denoted at Tropo-BC. Note that ORDY-BC is one kind of GCTM-LBC. The intention of the tropopause algorithm is an attempt to improve the ozone simulation at the surface. Figure 11 shows the RMSE for both Profile-BC and Tropo-BC. The results show that the RMSE in Profile-BC is always higher than the RMSE in Tropo-BC, where as the ORDY-BC have either greater or less than Profile BC depending on the locations. Although the differences between Profile-BC and Tropo-BC in RMSE was found to be within 1 to 2 ppbv in June and July, and 3 to 4 ppbv in January, the results have demonstrated the tropopause-determining algorithm has successfully prevented the high surface ozone estimates, which Tang and AlSaadi mentioned in their study.

\subsubsection{Tropo-BC}

For overall performance of Tropo-BC, we have included additional statistical analyses using all CASTNET data. Table 3 shows the summary of RMSE and mean bias (MB) for all three BCs. In the table, we have broken down the entire United States into three regions, which are West
Coast (West), Central United States (Central), and East Coast (East). The average RMSE for all three months in all stations is calculated to be $14.2 \mathrm{ppbv}, 13.3 \mathrm{ppbv}$, and $17.6 \mathrm{ppbv}$ for Profile-BC, Tropo-BC, and ORDY-BC, respectively. We observed that the RMSE in Tropo-BC is always lower than both Profile-BC and ORDY-BC for every region and every month. This demonstrates the Tropo-BC is the best method of generating lateral boundary condition for CMAQ. In the table, large differences (i.e., average in 3 ppbv) between Tropo-BC and Profile-BC are observed in the "West". It should be noted that this large RMSE improvement in the "West" was mainly contributed by the sites that are located in the State of Washington. The magnitude of changing RMSE in the State of Washington ranges from 4 to $12 \mathrm{ppbv}$. The poor performance of Profile-BC in RMSE in the "West" has shown that Profile$\mathrm{BC}$ has failed to estimate the impact from intercontinental transport of air pollutants from East Asia across the Pacific Ocean. Moreover, it fails to represent the actual geospatial variations of lateral boundary in the United States.

For the performance of Tropo-BC in all other regions, minor improvement is observed when compared with ProfileBC. Large improvement is found in month of January. Since Profile-BC uses a fixed BC concentration and this fixed BC concentration is usually higher than the actual background ozone in winter, as a result, overestimation of surface ozone in Profile-BC is observed. This demonstrates the importance of using dynamic BCs instead of the static BCs. Figure 13 shows the distributions of RMSE differences among these three scenarios for each of the CASTNET sites. If we consider $\pm 1 \mathrm{ppbv}$ as model variability, then we conclude that only $5 \%$ or less of the sites in Tropo-BC have poorer performance compared with Profile-BC. In these $5 \%$ of the sites, we have observed the Tropo-BC overestimated the nighttime ozone concentration in June.

In comparison with ORDY-BC, Tropo-BC is outperformed for every observation site in January. Strong improvement in Tropo-BC is found in both January and June. In the plot, we have observed $10 \%$ or less of the sites in Tropo-BC have poorer performance than in ORDY-BC (i.e., right side panel). We believed that this $10 \%$ is contributed by the nature of underestimation of ozone in $36 \mathrm{~km}$ resolution. Since the surface ozone in ORDY-BC is always higher than in Tropo-BC, the improvement may not actually be counted. For the overall performance, Tropo-BC has outperformed ORDY-BC in every month for all regions. These results, once again, demonstrate that the removal of stratospheric ozone using our tropopause-determining algorithm strongly improves the performance of surface ozone simulations in CMAQ.

\section{Conclusion}

In this study, we have successfully integrated our newly developed tropopause-determining algorithm, based on 
Table 3. Summary of NET-RMSE and average column temperatures for the sonde sites.

\begin{tabular}{|c|c|c|c|c|}
\hline & & Profile-BC & Tropo-BC & ORDY-BC \\
\hline \multirow[t]{8}{*}{ JANUARY } & ALL & $\mathrm{RMSE}=11.9 \mathrm{ppbv}$ & $\mathrm{RMSE}=10.3 \mathrm{ppbv}$ & $\mathrm{RMSE}=19.8 \mathrm{ppbv}$ \\
\hline & & $\mathrm{MB}=7.3 \mathrm{ppbv}$ & $\mathrm{MB}=3.9 \mathrm{ppbv}$ & $\mathrm{MB}=13.2 \mathrm{ppbv}$ \\
\hline & WEST & $\mathrm{RMSE}=16.8 \mathrm{ppbv}$ & $\mathrm{RMSE}=13.0 \mathrm{ppbv}$ & $\mathrm{RMSE}=23.5 \mathrm{ppbv}$ \\
\hline & & $\mathrm{MB}=14.6 \mathrm{ppbv}$ & $\mathrm{MB}=9.8 \mathrm{ppbv}$ & $\mathrm{MB}=18.3 \mathrm{ppbv}$ \\
\hline & CENTRAL & $\mathrm{RMSE}=10.1 \mathrm{ppbv}$ & $\mathrm{RMSE}=8.2 \mathrm{ppbv}$ & $\mathrm{RMSE}=23.6 \mathrm{ppbv}$ \\
\hline & & $\mathrm{MB}=6.6 \mathrm{ppbv}$ & $\mathrm{MB}=2.4 \mathrm{ppbv}$ & $\mathrm{MB}=16.1 \mathrm{ppbv}$ \\
\hline & EAST & $\mathrm{RMSE}=11.2 \mathrm{ppbv}$ & $\mathrm{RMSE}=10.1 \mathrm{ppbv}$ & $\mathrm{RMSE}=18.0 \mathrm{ppbv}$ \\
\hline & & $\mathrm{MB}=6.3 \mathrm{ppbv}$ & $\mathrm{MB}=3.2 \mathrm{ppbv}$ & $\mathrm{MB}=11.5 \mathrm{ppbv}$ \\
\hline \multirow[t]{8}{*}{ JUNE } & ALL & $\mathrm{RMSE}=14.3 \mathrm{ppbv}$ & $\mathrm{RMSE}=13.8 \mathrm{ppbv}$ & $\mathrm{RMSE}=16.4 \mathrm{ppbv}$ \\
\hline & & $\mathrm{MB}=0.3 \mathrm{ppbv}$ & $\mathrm{MB}=1.9 \mathrm{ppbv}$ & $\mathrm{MB}=7.2 \mathrm{ppbv}$ \\
\hline & WEST & $\mathrm{RMSE}=18.3 \mathrm{ppbv}$ & $\mathrm{RMSE}=15.2 \mathrm{ppbv}$ & $\mathrm{RMSE}=19.9 \mathrm{ppbv}$ \\
\hline & & $\mathrm{MB}=4.3 \mathrm{ppbv}$ & $\mathrm{MB}=2.0 \mathrm{ppbv}$ & $\mathrm{MB}=7.2 \mathrm{ppbv}$ \\
\hline & CENTRAL & $\mathrm{RMSE}=12.5 \mathrm{ppbv}$ & $\mathrm{RMSE}=11.3 \mathrm{ppbv}$ & $\mathrm{RMSE}=16.0 \mathrm{ppbv}$ \\
\hline & & $\mathrm{MB}=-4.5 \mathrm{ppbv}$ & $\mathrm{MB}=-1.3 \mathrm{ppbv}$ & $\mathrm{MB}=6.1 \mathrm{ppbv}$ \\
\hline & EAST & $\mathrm{RMSE}=14.1 \mathrm{ppbv}$ & $\mathrm{RMSE}=14.1 \mathrm{ppbv}$ & $\mathrm{RMSE}=15.9 \mathrm{ppbv}$ \\
\hline & & $\mathrm{MB}=1.1 \mathrm{ppbv}$ & $\mathrm{MB}=2.9 \mathrm{ppbv}$ & $\mathrm{MB}=7.6 \mathrm{ppbv}$ \\
\hline \multirow[t]{8}{*}{ JULY } & ALL & $\mathrm{RMSE}=16.3 \mathrm{ppbv}$ & $\mathrm{RMSE}=15.8 \mathrm{ppbv}$ & $\mathrm{RMSE}=16.6 \mathrm{ppbv}$ \\
\hline & & $\mathrm{MB}=4.2 \mathrm{ppbv}$ & $\mathrm{MB}=3.4 \mathrm{ppbv}$ & $\mathrm{MB}=5.3 \mathrm{ppbv}$ \\
\hline & WEST & $\mathrm{RMSE}=19.8 \mathrm{ppbv}$ & $\mathrm{RMSE}=16.9 \mathrm{ppbv}$ & $\mathrm{RMSE}=16.9 \mathrm{ppbv}$ \\
\hline & & $\mathrm{MB}=4.3 \mathrm{ppbv}$ & $\mathrm{MB}=4.1 \mathrm{ppbv}$ & $\mathrm{MB}=6.0 \mathrm{ppbv}$ \\
\hline & CENTRAL & $\mathrm{RMSE}=13.7 \mathrm{ppbv}$ & $\mathrm{RMSE}=13.3 \mathrm{ppbv}$ & $\mathrm{RMSE}=13.7 \mathrm{ppbv}$ \\
\hline & & $\mathrm{MB}=-2.4 \mathrm{ppbv}$ & $\mathrm{MB}=-3.1 \mathrm{ppbv}$ & $\mathrm{MB}=-1.4 \mathrm{ppbv}$ \\
\hline & EAST & $\mathrm{RMSE}=16.4 \mathrm{ppbv}$ & $\mathrm{RMSE}=16.3 \mathrm{ppbv}$ & $\mathrm{RMSE}=17.3 \mathrm{ppbv}$ \\
\hline & & $\mathrm{MB}=6.2 \mathrm{ppbv}$ & $\mathrm{MB}=6.1 \mathrm{ppbv}$ & $\mathrm{MB}=8.1 \mathrm{ppbv}$ \\
\hline
\end{tabular}

ALL - All stations; WEST - West of $115 \mathrm{~W}$; CENTRAL - Between $115 \mathrm{~W}$ and $94 \mathrm{~W}$; EAST - East of $94 \mathrm{~W}$; RMSE is root mean square error; MB is mean bias.

chemical tropopause definition, into the methodology of downscaling from the global chemical model (i.e., GEOSChem) into the regional air quality model (i.e., CMAQ). The purpose of the algorithm is to resolve the inconsistency of vertical structures between GEOS-Chem (i.e., containing both the tropospheric and stratospheric components) and CMAQ (containing only the tropospheric component). It identifies the height of tropopause from GCTM outputs and applies tropopause ozone concentration as the maximum ozone concentration at the CMAQ lateral boundary condition. As a result, it excludes any stratospheric ozone from being included in the regional air quality model. Since CMAQ is only designed for tropospheric application with no top boundary input, any stratospheric ozone or stratospheric intrusion should be considered inapplicable in CMAQ. In our results, we have found that the GCTM output (i.e., GEOS-Chem) with the tropopause-determining algorithm (i.e., Tropo-BC) always yields a better result than that with the fixed BCs (i.e., Profile-BC). Moreover, Tropo-BC also yields better results than that with the GCM BCs (i.e., ORDY-BC). For Profile-BC, we have observed the fixed BCs tend to overestimate surface ozone concentration during wintertime and underestimate in summertime. For ORDY-BC, strong over prediction of surface ozone is observed as a re- sult of stratospheric ozone from the upper atmosphere. These results are similar to the findings in Tang et al., where a large overestimation is observed in CMAQ surface ozone when applying GCTM-BC. Fortunately, using our new tropopause algorithm technique (i.e., Tropo-BC) with the global model input (i.e., GEOS-Chem), we have resolved the high surface ozone issue observed in GCTM-BC, while maintaining good vertical ozone prediction in the upper air. For further improving the model simulations, we recommended that all vertical layers from MM5 (i.e., 34 layers) should be used in CMAQ, instead of 19 layers created from vertical collapsing. This way, it will break down the original CMAQ top layer into 5 separated layers with a thickness of 1.0 to $1.5 \mathrm{~km}$ for vertical transport. It is believed that the top CMAQ layer (i.e., $6 \mathrm{~km}$ deep) is relatively too thick; it may give a wrong representation of transport of flux in the upper troposphere.

In statistical analysis, we have performed a correlation study on the average tropospheric column temperature and stratospheric effect using the RMSE differences between ORDY-BC and Tropo-BC. The results show that a break point temperature, which separates the temperature region between stratospheric effect and non-stratospheric effect in the chemical downscaling process, is about $252 \mathrm{~K}$. This value can be used as a quick check to see whether or not a particular 
region or day in the regional model is having a stratospheric effect from GCTM-BC. Nevertheless, this temperature is based on statistical analysis and may contain certain statistical errors. Therefore, we recommend only using this value as a screening tool.

In conclusion, we have demonstrated the advantage of using the tropopause-determining algorithm along with timevarying GCTM lateral BC for air quality predictions of the tropospheric ozone. We have advanced the exiting technique on how GCTM data can be incorporated into CMAQ lateral BC. This methodology can be applied on different GCTM data for downscaling purposes to yield a better surface ozone prediction in a regional CTM.

\section{Appendix A}

Table A1. GEOS-Chem to CMAQ IC/BC species mapping table.

\begin{tabular}{ll}
\hline CMAQ CB-IV specie & GEOS-CHEM species \\
\hline$\left[\mathrm{NO}_{2}\right]$ & {$\left[\mathrm{NO}_{\mathrm{x}}\right]$} \\
{$\left[\mathrm{O}_{3}\right]$} & {$\left[\mathrm{O}_{\mathrm{x}}\right]-\left[\mathrm{NO}_{\mathrm{x}}\right]$} \\
{$\left[\mathrm{N}_{2} \mathrm{O}_{5}\right]$} & {$\left[\mathrm{N}_{2} \mathrm{O}_{5}\right]$} \\
{$\left[\mathrm{HNO}_{3}\right]$} & {$\left[\mathrm{HNO}_{3}\right]$} \\
{$[\mathrm{PNA}]$} & {$\left[\mathrm{HNO}_{4}\right]$} \\
{$\left[\mathrm{H}_{2} \mathrm{O}_{2}\right]$} & {$\left[\mathrm{H}_{2} \mathrm{O}_{2}\right]$} \\
{$[\mathrm{CO}]$} & {$[\mathrm{CO}]$} \\
{$[\mathrm{PAN}]$} & {$[\mathrm{PAN}]+[\mathrm{PMN}]+[\mathrm{PPN}]$} \\
{$[\mathrm{MGLY}]$} & {$[\mathrm{MP}]$} \\
{$[\mathrm{ISPD}]$} & {$[\mathrm{MVK}]+[\mathrm{MACR}]$} \\
{$[\mathrm{NTR}]$} & $1 / 2\left[\mathrm{R}_{4} \mathrm{~N}_{2}\right]$ \\
{$[\mathrm{FORM}]$} & {$[\mathrm{CH} 2 \mathrm{O}]$} \\
{$[\mathrm{ALD} 2]$} & {$[\mathrm{ALD} 2]+[\mathrm{RCHO}]$} \\
{$[\mathrm{PAR}]$} & $1 / 4[\mathrm{ALK} 4]+1 / 3\left[\mathrm{C}_{3} \mathrm{H}_{8}\right]+$ \\
& $10 / 4\left[\mathrm{C}_{2} \mathrm{H}_{6}\right]+$ \\
& $1 / 3[\mathrm{ACET}]+$ \\
& $1 / 4[\mathrm{MEK}]+$ \\
{$\left[\mathrm{OLE}^{2}\right]$} & $1 / 2[\mathrm{PREPE}]$ \\
{$[\mathrm{ISOP}]$} & $1 / 2[\mathrm{PRPE}]$ \\
{$\left[\mathrm{SO}_{2}\right]$} & {$\left[\mathrm{ISOP}^{2}\right]$} \\
{$\left[\mathrm{NH}_{3}\right]$} & {$\left[\mathrm{SO}_{2}\right]$} \\
{$\left[\mathrm{ASO}_{4} \mathrm{~J}\right]$} & {$\left[\mathrm{NH}_{3}\right]$} \\
{$\left[\mathrm{ANH}_{4} \mathrm{~J}\right]$} & {$\left[\mathrm{SO}_{4}\right]$} \\
{$\left[\mathrm{ANO}_{3} \mathrm{~J}\right]$} & {$\left[\mathrm{NH}_{4}\right]$} \\
& {$\left[\mathrm{NO}_{3}\right]$} \\
&
\end{tabular}

Acknowledgements. This work was supported by the US Environmental Protection Agency under STAR Agreement R830959 and the Intercontinental transport and Climatic effects of Air Pollutants (ICAP) project. It has not formally been reviewed by the EPA. The views presented in this document are solely those of the authors and the EPA does not endorse any products or commercial services mentioned in this publication. We also thank NSF funded National Institute of Computational Sciences for us to use Kraken supercomputer on this study.

Edited by: F. Dentener

\section{References}

Al-Saadi, J., Pierce, B., McQueen, J., Natarajan, M., Kuhl, D., Tang, Y. H., Schaack, T. K., and Grell, G.: Global Forecasting System (GFS) Project: Improving National chemistry forecasting and assimilation capabilities, Applications of Environmental Remote Sensing to Air Quality and Public Health, Potomac, MD, 8-9 May 2007.

Bertschi, I. T., Jaffe, D. A., Jaegle, L., Price, H. U., and Dennison, J. B.: 2002 airborne observations of trans-Pacific transport of ozone, $\mathrm{CO}$, volatile organic compounds, and aerosols to the northeast Pacific: Impacts of Asian anthropogenic and Siberian boreal fire emissions, J. Geophys. Res., 109, D23S12, doi:10.1029/2003JD004328, 2004.

Bethan, S., Vaughan, G., and Reid, S. J.: A comparison of ozone and thermal tropopause heights and the impact of tropopause definition on quantifying the ozone content of the troposphere, Q. J. Roy. Meteor. Soc., 122, 929-944, 1996.

Byun, D. and Schere, K. L.: Review of the governing equations, computational algorithms, and other components of the models3 Community Multiscale Air Quality (CMAQ) modeling system, Appl. Mech. Rev., 59, 51-77, 2006.

Byun, D. W., Moon, N. K., Jacob, D., and Park, R.: Regional transport study of air pollutants with linked global tropospheric chemistry and regional air quality models, 2nd ICAP Workshop, Research Triangle Park, NC, USA, 2004.

Chin, M., Diehl, T., Ginoux, P., and Malm, W.: Intercontinental transport of pollution and dust aerosols: implications for regional air quality, Atmos. Chem. Phys., 7, 5501-5517, 2007, http://www.atmos-chem-phys.net/7/5501/2007/.

Collins, W. J., Derwent, R. G., Garnier, B., Johnson, C. E., Sanderson, M. G., and Stevenson, D. S.: Effect of stratospheretroposphere exchange on the future tropospheric ozone trend, J. Geophys. Res., 108(D12), 8528, doi:10.1029/2002JD002617, 2003.

Eder, B., and Yu, S. C.: A performance evaluation of the 2004 release of Models-3 CMAQ, Atmos. Environ., 40, 4811-4824, 2006.

Fiore, A., Jacob, D. J., Liu, H., Yantosca, R. M., Fairlie, T. D., and $\mathrm{Li}, \mathrm{Q} .:$ Variability in surface ozone background over the United States: Implications for air quality policy, J. Geophys. Res., 108(D24), 4787, doi:10.1029/2003JD003855, 2003.

Fu, J. S., Jang, C. J., Streets, D. G., Li, Z. P., Kwok, R., Park, R., and Han, Z. W.: MICS-Asia II: Modeling gaseous pollutants and evaluating an advanced modeling system over East Asia, Atmos. Environ., 42, 3571-3583, 2008.

Fusco, A. C. and Logan, J. A.: Analysis of 1970-1995 trends in tropospheric ozone at Northern Hemisphere midlatitudes with the GEOS-CHEM model, J. Geophys. Res., 108(D15), 4449, doi:10.1029/2002JD002742, 2003.

Heald, C. L., Jacob, D. J., Fiore, A. M., Emmons, L. K., Gille, J. C., Deeter, M. N., Warner, J., Edwards, D. P., Crawford, J. H., Hamlin, A. J., Sachse, G. W., Browell, E. V., Avery, M. A., Vay, S. A., Westberg, D. J., Blake, D. R., Singh, H. B., Sandholm, S. T., Talbot, R. W., and Fuelberg, H. E.: Asian outflow and transPacific transport of carbon monoxide and ozone pollution: An integrated satellite, aircraft, and model perspective, J. Geophys. Res., 108(D24), 4804, doi:10.1029/2003JD003507, 2003.

Heald, C. L., Jacob, D. J., Park, R. J., Alexander, B., Fairlie, T. D., Yantosca, R. M., and Chu, D. A.: Trans-Pacific transport 
of Asian anthropogenic aerosols and its impact on surface air quality in the United States, J. Geophys. Res., 111, D14310, doi:10.1029/2005JD006847, 2006.

Hoinka, K. P.: The tropopause: discovery, definition, and demarcation, Meteorol. Z., 6, 281-303, 1997.

Holton, J. R., Haynes, P. H., McIntyre, M. E., Douglass, A. R., Rood, R. B., and Pfister, L.: Stratosphere-Troposphere Exchange, Rev. Geophys., 33, 403-439, 1995.

Lam, Y. F., Fu, J. S., Gao, Y., Jacob, D., and Park, R.: Downscaling effects of GEOS-Chem as CMAQ Initial and Boundary Conditions: "Tropopause effect", The 7th Annual CMAS Conference, Chapel Hill, NC, USA, 2008.

Li, Z., Fu, J. S., Jang, C., Wang, B., Mathur, R., Park, R., and Jacob, D.: Evaluation of GEOS-CHEM/CMAQ Interface Over China and US, The 2nd GEOS-Chem Users' Meeting, Cambridge, MA, USA, April, 2005.

Liang, Q., Jaegle, L., Hudman, R. C., Turquety, S., Jacob, D. J., Avery, M. A., Browell, E. V., Sachse, G. W., Blake, D. R., Brune, W., Ren, X., Cohen, R. C., Dibb, J. E., Fried, A., Fuelberg, H., Porter, M., Heikes, B. G., Huey, G., Singh, H. B., and Wennberg, P. O.: Summertime influence of Asian pollution in the free troposphere over North America, J. Geophys. Res., 112, D12S11, doi:10.1029/2006JD007919, 2007.

Lin, J. T., Wuebbles, D. J., and Liang, X. Z.: Effects of intercontinental transport on surface ozone over the United States: Present and future assessment with a global model, Geophys. Res. Lett., 35, L02805, doi:10.1029/2007GL031415, 2008.

Liu, X., Chance, K., Sioris, C. E., Kurosu, T. P., Spurr, R. J. D., Martin, R. V., Fu, T. M., Logan, J. A., Jacob, D. J., Palmer, P. I., Newchurch, M. J., Megretskaia, I. A., and Chatfield, R. B.: First directly retrieved global distribution of tropospheric column ozone from GOME: Comparison with the GEOS-CHEM model, J. Geophys. Res., 111, D02308, doi:10.1029/2005JD006564, , 2006.

Martin, R. V., Jacob, D. J., Logan, J. A., Bey, I., Yantosca, R. M., Staudt, A. C., Li, Q. B., Fiore, A. M., Duncan, B. N., Liu, H. Y., Ginoux, P., and Thouret, V.: Interpretation of TOMS observations of tropical tropospheric ozone with a global model and in situ observations, J. Geophys. Res., 107(D18), 4351, doi:10.1029/2001JD001480, 2002.

Mathur, R., Lin, H. M., McKeen, S., Kang, D., and Wong, D.: Three-dimensional model studies of exchange processes in the troposphere: use of potential vorticity to specify aloft $\mathrm{O}_{3}$ in regional models, The 7th Annual CMAS Conference, Chapel Hill, NC, USA, 2008.

McPeters, R. D., Labow, G. J., and Logan, J. A.: Ozone climatological profiles for satellite retrieval algorithms, J. Geophys. Res., 112, D05308, doi:10.1029/2005JD006823, 2007.

Morris, R. E., McNally, D. E., Tesche, T. W., Tonnesen, G., Boylan, J. W., and Brewer, P.: Preliminary evaluation of the community multiscale air, quality model for 2002 over the southeastern United States, J. Air Waste Manage., 55, 1694-1708, 2005.

Morris, R. E., Koo, B., Tesche, T. W., Loomis, C., Stella, G., Tonnesen, G., and Wang, Z.: VISTAS Emissions and Air Quality Modeling - Phase I Task 6 Report: Modeling Protocol for the VISTAS Phase II Regional Haze Modeling, Novato, CA, USA, 2006.

Newchurch, M. J., Ayoub, M. A., Oltmans, S., Johnson, B., and Schmidlin, F. J.: Vertical distribution of ozone at four sites in the United States, J. Geophys. Res., 108(D1), 4031, doi:10.1029/2002JD002059, 2003.

Ordonez, C., Brunner, D., Staehelin, J., Hadjinicolaou, P., Pyle, J. A., Jonas, M., Wernli, H., and Prevot, A. S. H.: Strong influence of lowermost stratospheric ozone on lower tropospheric background ozone changes over Europe, Geophys. Res. Lett., 34, L07805, doi:10.1029/2006GL029113, 2007.

Park, R. J., Jacob, D. J., Chin, M., and Martin, R. V.: Sources of carbonaceous aerosols over the United States and implications for natural visibility, J. Geophys. Res., 108(D12), 4355, doi:10.1029/2002JD003190, 2003.

Park, R. J., Jacob, D. J., Field, B. D., Yantosca, R. M., and Chin, M.: Natural and transboundary pollution influences on sulfate-nitrate-ammonium aerosols in the United States: Implications for policy, J. Geophys. Res., 109, D15204, doi:10.1029/2003JD004473, 2004.

Park, R. J., Jacob, D. J., Kumar, N., and Yantosca, R. M.: Regional visibility statistics in the United States: Natural and transboundary pollution influences, and implications for the Regional Haze Rule, Atmos. Environ., 40, 5405-5423, 2006.

Perez, C., Jimenez, P., Jorba, O., Sicard, M., and Baldasano, J. M.: Influence of the PBL scheme on high-resolution photochemical simulations in an urban coastal area over the Western Mediterranean, Atmos. Environ., 40, 5274-5297, 2006.

Song, C. K., Byun, D. W., Pierce, R. B., Alsaadi, J. A., Schaack, T. K., and Vukovich, F.: Downscale linkage of global model output for regional chemical transport modeling: Method and general performance, J. Geophys. Res., 113, D08308, doi:10.1029/2007JD008951, 2008.

Stohl, A., Bonasoni, P., Cristofanelli, P., Collins, W., Feichter, J., Frank, A., Forster, C., Gerasopoulos, E., Gaggeler, H., James, P., Kentarchos, T., Kromp-Kolb, H., Kruger, B., Land, C., Meloen, J., Papayannis, A., Priller, A., Seibert, P., Sprenger, M., Roelofs, G. J., Scheel, H. E., Schnabel, C., Siegmund, P., Tobler, L., Trickl, T., Wernli, H., Wirth, V., Zanis, P., and Zerefos, C.: Stratosphere-troposphere exchange: A review, and what we have learned from STACCATO, J. Geophys. Res., 108(D12), 8516, doi:10.1029/2002JD002490, 2003.

Streets, D. G., Fu, J. H. S., Jang, C. J., Hao, J. M., He, K. B., Tang, X. Y., Zhang, Y. H., Wang, Z. F., Li, Z. P., Zhang, Q., Wang, L. T., Wang, B. Y., and Yu, C.: Air quality during the 2008 Beijing Olympic Games, Atmos. Environ., 41, 480-492, 2007.

Tagaris, E., Manomaiphiboon, K., Liao, K. J., Leung, L. R., Woo, J. H., He, S., Amar, P., and Russell, A. G.: Impacts of global climate change and emissions on regional ozone and fine particulate matter concentrations over the United States, J. Geophys. Res., 112, D14312, doi:10.1029/2006JD008262, 2007.

Tang, Y. H., Carmichael, G. R., Thongboonchoo, N., Chai, T. F., Horowitz, L. W., Pierce, R. B., Al-Saadi, J. A., Pfister, G., Vukovich, J. M., Avery, M. A., Sachse, G. W., Ryerson, T. B., Holloway, J. S., Atlas, E. L., Flocke, F. M., Weber, R. J., Huey, L. G., Dibb, J. E., Streets, D. G., and Brune, W. H.: Influence of lateral and top boundary conditions on regional air quality prediction: A multiscale study coupling regional and global chemical transport models, J. Geophys. Res., 112, D10S18, doi:10.1029/2006JD007515, 2007.

Tang, Y. H., Lee, P., Tsidulko, M., Huang, H. C., McQueen, J. T., DiMego, G. J., Emmons, L. K., Pierce, R. B., Thompson, A. M., Lin, H. M., Kang, D., Tong, D., Yu, S. C., Mathur, R., Pleim, J. 
E., Otte, T. L., Pouliot, G., Young, J. O., Schere, K. L., Davidson, P. M., and Stajner, I.: The impact of chemical lateral boundary conditions on CMAQ predictions of tropospheric ozone over the continental United States, Environ. Fluid Mech., 9(1), 43-58, doi:10.1007/s10652-008-9092-5, 2008.

Tesche, T. W., Morris, R., Tonnesen, G., McNally, D., Boylan, J., and Brewer, P.: CMAQ/CAMx annual 2002 performance evaluation over the eastern US, Atmos. Environ., 40, 4906-4919, 2006.

Vingarzan, R.: A review of surface ozone background levels and trends, Atmos. Environ., 38, 3431-3442, 2004.
WMO, Atmospheric ozone, 1985: WMO Global Ozone Res. and Monit. Proj. Rep. 20, World Meteorological Organization (WMO), Geneva, Switzerland, 1986.

Zangl, G., Gohm, A., and Obleitner, F.: The impact of the PBL scheme and the vertical distribution of model layers on simulations of Alpine foehn, Meteorology and Atmospheric Physics, 99, 105-128, 2008. 